\title{
Investigating Social Justice Topics in Reading Texts of English Textbooks Used in China and Germany
}

\begin{abstract}
Xiao Zhang
Faculty of Foreign Languages and Literature, Ludwig-Maximilians-Universität München, Munich, Germany

Abstract-English language teaching (ELT) plays a vital role in promoting social equality and societal transformation. Thus, social justice education has been given attention as one of ELT purposes. Textbooks, as the most significant teaching materials of English teachers, pose significant effects on English learners' awareness of social justice issues that touch upon their daily lives. However, there is little empirical research investigating integrated social justice topics in ELT textbooks. This study addressed the gap through identifying and comparing social justice topics of grade 10 English textbooks used in Chinese and German high school classrooms. Results of this study revealed that German English textbooks encompassed a much more diversity of social justice topics than Chinese English textbooks. Besides, this study offered a significant capacity for English textbooks to stimulate English learners' social responsibility and awareness of social justice. This study has implications for improving social justice education in the ELT classroom.
\end{abstract}

Index Terms -social justice education, textbooks, social justice topics, China, Germany

\section{INTRODUCTION}

Humans are living in a world which is against a backdrop of sharp inequalities, persisting exclusion and environmental damages. According to the World Inequality Report 2018 Executive Summary (Alvaredo et al., 2018), almost everywhere in the worldwide is confronting income inequality, economic inequality, wealth inequality. Except for negative influences exerted on human societies, environmental inequality is also becoming one of the social concerns. Environmental inequality received attention in the late 1980s and early 1990s. Environmental hazards disproportionately burden the poor, working classes and people of colour. They have less access to environmental amenities, such as parks, open space and wilderness areas than do whites and wealthier individuals. Disappointingly, their problems and environmental concerns are ignored by mainstream environmental organisations (Downey, 2005). Consequently, these inequalities resulting from human actions force a multitude of people to encounter more challenges and tend to be more vulnerable to disasters and tragedies.

English language classroom is an opportunity for students to understand social justice topics. As national and global citizens, English learners should not only equip themselves with foreign language knowledge, concepts and skills but also be responsible for re-structuring a socially just environment. Furthermore, they should enable themselves to employ critical thinking skills and their impartiality with an ethic of caring when they identify underneath notions behind social injustice. Thus, ELT needs to carry out these social concerns.

Textbooks are one of the primary content providers for English teaching, and they are significant in shaping cultural, social attitudes and in moulding social behaviour of language learners (Ahmad \& Shah, 2014, p. 12). Thus, reading texts with social justice topics are influential for students since students are exposed to real social situations. Through reading those texts, students learn to recognise social inequalities and raise awareness of social inclusiveness, social justice protection and social actions.

Although social justice education in ELT receives attention in recent years, there is little empirical research examining what social justice topics are displayed to English learners. To address the gap, this study investigated the social justice topics of English textbooks used in China and Germany. To establish a framework, it starts with an overview of theories and previous studies, followed by a brief examination of the relevance of social justice education and textbooks. This study consists of a qualitative content analysis of texts relating to social justice topics in three books. Afterwards, it discussed the analysis results and provided evaluations on these textbooks.

\section{LITERATURE REVIEW}

\section{A. ELT Textbooks}

ELT textbook, as a primary teaching aid, is indispensable for the language classroom. Most teachers consider it as a basis for teaching contents and benefit from its tasks. In general, teachers organise various activities from textbook topics. Connecting to such topics, teachers prepare writing assignments, build onto discussion tasks, assign extra reading materials. These activities help learners not only with linguistic performance but also with psychological, 
ethical and interpersonal development - and to expect them to formulate the worldview and philosophy of life (Stubbs, 1982, p. 138). Therefore, topics deriving from textbooks are crucial for various forms of classroom activities and discussions. Besides, English learners are emotionally and cognitively affected by textbook contents. In the learning process, students have the reading experience of various contents relating to life, culture or society. In other words, the textbook may be the first interaction with social topics for learners in a foreign language.

Textbooks are considered as a unique resource, and they are used to shape the values, knowledge and attitudes of the next generation. Textbooks result from a complicated production process, including myriad educational stakeholders and individuals. Since this process certainly involves multiple compromises among different or even opposite perspectives, textbooks can reflect and co-constitute what is commonly accepted as sayable in a time/space among certain groups of people (Macgilchrist, 2018, p. 525).

Cunningsworth (1995) argues that using English textbooks is to provide a better model of language use than describing some imaginary non-existent construct, and at the same time to motivate learners. With the guidance of textbooks, students may learn better when they are not only concentrating on learning the target language but are also using the language to accomplish other things or to learn about different subjects. Olshtain and Celce-Murcia (2000) offer a description of texts and subordinated activities. They demonstrate that the basic unit of language teaching analysis is to use sentences signalling an approach which legitimises decontextualised language practice. They also notice that recent approaches to language learning and teaching tend to pick up discourse or text as the basic unit of analysis. They claim that:

More recent language textbooks present texts, short or long, as a basis for both understanding and practising language use within broader meaningful contexts. This approach has dramatically altered the type of activities undertaken in language classrooms. Learners need to focus, therefore, on various discourse features within any specified language activity (Olshtain \& Celce-Murcia, 2000, p. 708).

In the book The Practice of English Language Teaching, Harmer (2007) clarifies benefits and restrictions of textbooks. He argues that good textbooks are carefully prepared so that they are helpful with teacher's guidance, procedures for teaching suggestions, alternatives, extra activities and resources. If textbooks are inappropriately used, teachers and students might lose interest and be demotivated by contents.

All in all, the views presented so far have put significant importance on textbooks. The following section will address the relevance of topics in textbooks.

\section{B. Topics in Textbooks}

The textbook is necessary for facilitating language learning; it cannot merely do more because the language must be used in authentic situations for real purposes (Cunningsworth, 1995, p. 86). Thus, textbooks must contain subject matters and deal with topics of various kinds. In the past, scholars have initiated several pieces of research on textbook topics from a different point of views. These previous researches on textbooks topics support the importance of this paper. Indeed, those researches have conflicting thoughts, but they make contributions to study further.

Harmer (2007) contends the importance of textbook topics. He argues that textbooks can be highly reliable if visual and topic appeal presented in texts have a powerfully engaging effect. Thus, it safely claims that textbooks with a variety of topics lead learners to a productive and engaging reading process. Ur (1991) emphasises the possibility to base the language teaching around situations. That is, language teaching should build upon communicative events. These events can be called topics. Learners should be able to perceive and understand the underlying theme and the language which is used to express the issue.

Except for contributions textbooks have, Cunningsworth (1995) further articulates the connection between course materials and embedded topics. He admits that course materials which fail to include relevant and interesting topics are in danger of losing the attention of learners. Besides, he comes up with the idea that contents should create an authentic response which informs, challenges, stimulates, and encourages curiosity and develops judgement, and does other things that real language does. Only if the textbook is meaningful content based can students be able to create informed opinions, express their thoughts, form their conclusions, communicate those conclusions, discuss and justify specific issues.

Besides, there are also studies investigating topics from cultural perspectives. For instance, McKay (2003) claims the significance of topics. She articulates that textbooks should include topics of local culture because learners are given opportunities to communicate with others about their own culture in English. However, her data collected about teachers' beliefs on topics show the preference for international issues. The majority of teachers in the study believe that textbook topics should involve various cultures rather than local or English-speaking cultures. Thus, her study shows the contradiction of views on topics selection between researchers and teachers.

Gómez Rodríguez (2015) analyses surface and deep cultural topics in three English textbooks. As his analysis shows, these books are more surface culture oriented, including topics of pets, shopping, well-known mysteries, stressful situations and unusual hobbies among others, but components of deep culture are absent.

\section{Textbook Topics: Intersection of Social Justice Education and Textbooks}

\section{Social Justice Education}

Social justice education integrates various teaching approaches, including democratic education, critical pedagogy, 
critical multicultural education and culturally responsive education, along with elements of social, cognitive and systems theory and its purpose is to affect holistic educational and societal transformation (Dover, 2013, p. 6), which terms as "teaching for social justice". Social justice education has a powerful influence on students" academic achievement as well as social participation. Within its educational framework, students are educated to appreciate and inclined to participate in social justice concerns (Cohen, cited in Letizia 2017). Furthermore, Sandel argues that every person should do the right thing, and it is a central disposition of citizenship (Sandel, cited in Litizia 2017). Lickona and Davidson state that a central tenet of a person is merely knowing the difference between right and wrong and acting on it, and this is what social justice education strives for. Besides, social justice education also involves the recognition of the plight of the poor and the weak of communities (Lickona \& Davidson, cited in Litizia 2017).

To prove contributions to social justice education make regarding students' language teaching and improving students' ability to resolve social issues, Learning and Teaching Resources for Learning English through Social Issues offers a detailed framework. This document is published by the Hong Kong Education Bureau, China and is a guidebook for senior secondary English teachers about how to use social issues to improve students' language skills and social issues recognition. Based on the guidance, teachers can refer to activities/materials to help students work on various focuses. The following is one excerpt:

Lessons 5-8: Causes of a social problem (please refer to SoWs pp.96-97)

Activity 1

Work on the following in groups of 4 .

1. Read the article provided by your teacher, e.g. the article on p.8 (or the one you have collected).

2. Discuss where in the article the causes of the social problem identified are given.

3. Report to the class what you have found out about the causes of the social problem identified (i.e. what the causes are, and how details and examples are given to explain/illustrate them).

4. Read the article again and highlight the expressions for identifying causes.

5. Suggest and make a list of other expressions that can be used to identify causes.

6. Share with the class the expressions that you have come up with.

Activity 2

In the same group,

1. Select one or two social problems to work on.

2. For each social problem:

- Consider the most significant causes.

- List the causes according to their order of significance (i.e. from the most significant to the least significant).

- Discuss how details and examples are given to explain/illustrate each of the causes. For clarity, you may use a mind map to organise your ideas.

- Write a paragraph that presents the causes. The paragraph should start with a topic sentence that introduces the causes of the social problem. If you have sufficient information, you may choose to write a few short paragraphs, each of which focuses on one cause and starts with a topic sentence.

3. Present orally the paragraph(s) that you have written.

4. Listen to the presentations of other groups and give comments.

Teachers'notes

*For Activity 1, teachers might like to refer to the handout "Useful Expressions for Identifying Cause and Effect" on p.5 of the resources for expressions to be added to the list produced by students.

*For Activity 2, teachers might like to make use of the examples in the handout "Examples of Mind Map" on p.6 of the resources to demonstrate how, with the use of a mind map, details and examples can be used to illustrate causes. (Hong Kong Education Bureau, China, 2007, p3)

Therefore, social justice education goes without saying that it offers learners with the necessary skills to enhance their intellectual, moral and ethical development. Furthermore, students are encouraged to participate in social transformation. Social justice education implicitly instils national moral and civic values through exploring justice and injustice issues presented in learning contents. It also transports students to own a more expansive overview, e.g. with global and critical intercultural awareness.

\section{Topics in Textbook and Social Justice Education}

Social justice education in the ELT classroom is not easy to implement and achieve. It integrates aspects of teachers (e.g. social awareness; teaching approaches and organisations), coursebook (e.g. topics; exercises) and students (e.g. language levels; interests). As previously mentioned, teachers and students highly depend on textbooks based on textbook unit topics. Thus, when investigating the relationship between social justice education and textbooks, it can be analysed focusing on the intersection of reading subjects, that is, text topics. According to the interactive reading model developed by David E. Rumelhart (1976), reading refers not only the interaction between reader and the text but also the interaction between information the reader obtains by decoding and interpreting. Readers use both knowledge of word structure and background knowledge to interpret what they read. When students read texts about social (in) justice 
issues, the decoding process will re-construct readers' cognitive system towards society.

Although studies cited above are necessary for demonstrating the importance of topics in English textbooks on stimulating students' interest and promoting learning outcomes, they merely put attention on different cultures, and little research investigates topics about social justice concerns. The present study aims to fill this gap based on detailed categorisation into social justice aspects. Hence, this study attempts to answer the following questions:

a) What social justice topics of reading texts in grade 10 English textbooks have in China and Germany?

b) What differences and similarities do Chinese and German textbooks have in terms of social justice topics?

\section{RESEARCH DESIGN}

\section{A. Research Background}

This study examined grade 10 English textbooks in terms of social justice topics used in China and Germany based on three reasons. At first, both China and Germany set up educational policies to promote English acquisition as a foreign language. Therefore, China and Germany are EFL settings, which prove the availability of this study. Secondly, China and Germany stand for two different cultural representations and political ideologies. They are vital nations in Asia and Europe. Thus, it offers interest and impetus to analyse how their textbooks are different. Thirdly, this study chooses English textbooks for grade 10, which is the start of Chinese high school. In this period, students begin to shape their values toward life, society and the world. Besides, they begin to be involved in and gather knowledge about social issues. Hence, it is of much significance to analyse textbooks of this time.

\section{B. Sampling}

This study employed purposive sampling for textbooks selection. Purposive sampling means "the researcher is deciding as to what units he or she deems appropriate to include in the sample (Neuendorf, 2002, p. 88)". In this study, the author selected three English textbooks (two for China and one for Germany). For the sake of homogenisation, the author chooses textbooks which are designed for learners of grade 10.

The book series used in China consists of two books, which are published by Beijing Normal University Press. They are called Senior High English 1 [Compulsory Module] and Senior High English 2 [Compulsory Module]. The former book is for the first half-year of grade 10, and the latter book is for the second half-year. The English textbook selected for Germany is Green Line New 6, which is published in 2008. Currently, it is used in the state of Bavaria, Germany.

\section{Research Method}

To categories textbook topics in an organised manner, this study refers to nine social justice areas which are explicitly listed by United Nations document Social Justice in an Open World (United Nations, 2006). They include:

- Distribution of Income

- Distribution of Assets (capital, physical such as land and buildings)

- Equal Opportunities for work and employment

- Quality education and access to knowledge

- Health services, social security and the provision of a safe environment

- Opportunities for civic and political participation

- Equal rights between women and men

- Ethnic and other minority groups

- Persons with disabilities

In conducting the analysis, the author employed the qualitative content analysis to gain an in-depth understanding of the situation. Hsieh and Shannon explain the qualitative content analysis as "a research method for the subjective interpretation of the content of the text data through the systematic classification process of coding and identifying themes or patterns (Hsieh \& Shannon, 2005, p. 1278)". This study uses a manifest analysis through which "the researcher describes what the informants say, stays very close to the text, uses the words themselves, and describes the visible and obvious in the text (Hsieh \& Shannon, 2005, p. 1278)".

\section{Data Analysis Procedure}

This study followed a multi-step process:

1). Identified all English reading texts for the analysis.

2). Identified social justice topics covered from English reading texts and classified them. Those organised topics are in forms of word, phrases or sentences.

3). Compared topic coverage across China's and Germany's textbooks.

In the research process, one topic was counted only once even if this topic occurred more than one time. If one text covered two and more than two social justice topics, each case was counted separately. Besides, all selected reading texts are in English. Thus, German texts in Green Line New 6 were excluded from the analysis.

\section{FINDINGS AND DISCUSSIONS}


This section begins with an overall distribution of topics in three textbooks. Then, it is followed by an inventory of social justice topics covered in three books. The overview of topics in texts not only enables the researcher to have an exact "topic checklist" for the analysis but also helps to have a summary of social topics coverage. Then, further comparisons among three textbooks are presented.

\section{A. Identified Social Topics}

Going through a careful investigation of reading texts, Fig. 1 shows the distribution of social justice topics in three coursebooks. There are 44 social justice topics collected using locating keywords and themes raised from texts.

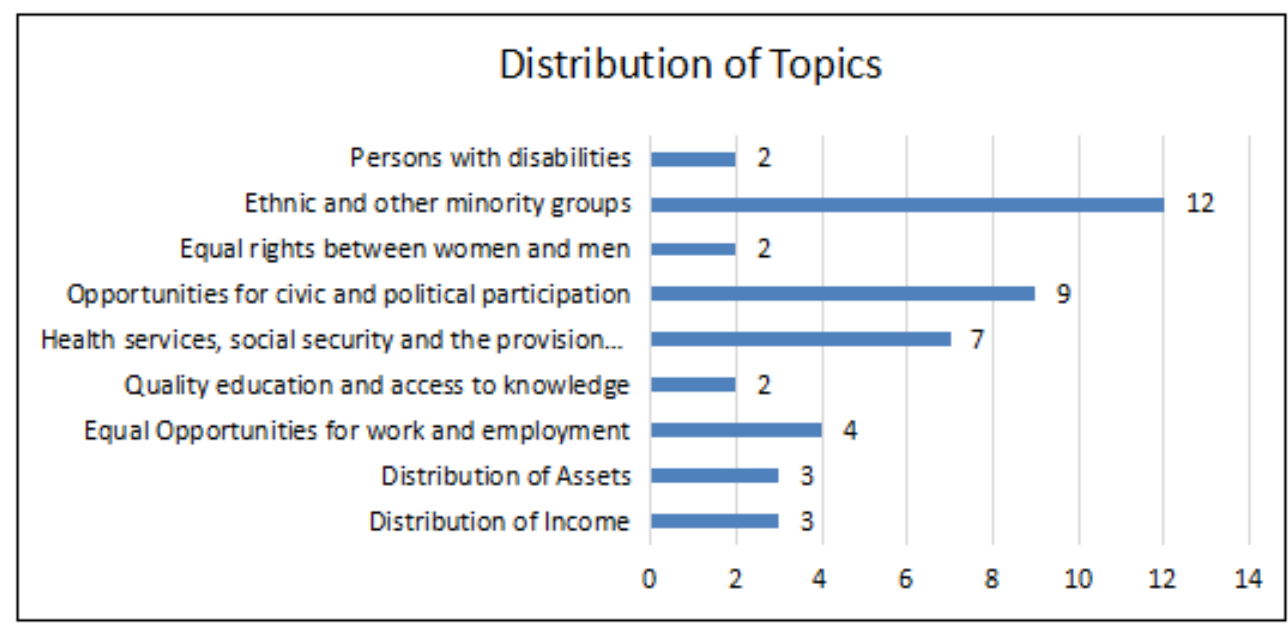

Figure 1. Distribution of Topics in Three English Coursebooks

As the chart illustrates, top three social justice topics which occur the most frequently are ethnic and other minority groups, opportunities for civic and political participation and health services, social security and the provision of a safe environment. Other topics seem to be evenly dispensed.

The following is a list of all identified social justice topics under nine main categories.

- Distribution of Income

1. Poverty in UK districts

2. Poverty in South Africa

3. Poverty in the USA

- Distribution of Assets

1. living, working and play together among races

2. less access to meat and more about disappears into crowds

3. the economic stagnation of minority community

- Equal Opportunities for work and employment

1. A lack of working opportunities for UK immigrants

2. Young Bangladeshi males with no employment

3. Unemployment in South Africa

4. Business and the government are not doing enough to hire young people and provide work experience

- Quality education and access to knowledge

1. Bottom of rankings of educational achievement in UK distribution

2. Education has improved in South Africa

- Health services, social security and the provision of a safe environment

1. Drug abuse

2. Crime

3. Violence

4. Bad living conditions

5. HIV/Aids

6. Wildlife trade

7. Crime in cyberspace and young hackers

- Opportunities for civic and political participation

1. Student's opinion towards liberty

2. Civil rights and democracy

3. Freedom and equal rights movement

4. Young people and students' rights

5. Respect each other

6. Human rights abuse 
7. Political crimes

8. Freedom of expression and assembly

9. Protest against nuclear testing in Asia pacific

- Equal rights between women and men

1. Unfair in career

2. Domestic violence

- Ethnic and other minority groups

1. Muslims, Hindus and Sikhs from India

2. Whites

3. Asians

4. British Pakistani

5. Bangladeshis

6. Hate groups

7. Native Africans

8. Racial segregation

9. Black power

10. Maori

11. African slaves

12. Celt

- Persons with disabilities

1. Promoting medical research into back injuries

2. Disabled people

\section{B. Results}

This part focuses on comparing the coverage of different social justice topics among textbooks. It offers a detailed overview of text topics. Since China's English textbooks are composed of two books, identified topic units are merged into one column.

Distribution of Income

As shown in Table 1, Green Line New 6 covers more topics relating to 'distribution of income' and mainly focuses on the context of the UK and South Africa, both of which are geographically close to Germany, while Senior High English series include USA related topics in reading texts.

TABLE 1.

COMPARISON OF THE TOPIC 'DISTRIBUTION OF INCOME

\begin{tabular}{|l|l|l|}
\hline Topics & Occurs or Not (Y= Yes, N=No) \\
\hline & Green Line New 6 (Germany) & Senior High English (China) \\
\hline Distribution of Income & & \\
\hline 1. Poverty in UK districts & Y & N \\
\hline 2. Poverty in South Africa & Y & N \\
\hline 3. Poverty in the USA & N & Y \\
\hline
\end{tabular}

Distribution of Assets, Equal Opportunities for Work and Employment, Quality Education and Access to Knowledge and Equal Rights between Women and Men

Students who start their study at high school are at the threshold of shaping values and gathering knowledge toward society and the world. They are living with an independent initiative to encounter radical moral and political challenges from what they read. There are debates over whether textbook contents should touch upon negative aspects of the society: should students explore real situations and notions of darkness within learning or is it necessary for students to acquire skills in the classroom which is full of a fabric of perfectness and positivity?

Regarding the debate, English textbooks in China and Germany seem to vote for the opposite side. As Table 2 illustrates, social justice topics under 'distribution of assets', 'equal opportunities for work and employment', 'quality education and access to knowledge' and 'equal rights between women and men' are integrated in Green Line New 6. Nevertheless, none of them is found in Senior High English. 
TABLE 2 .

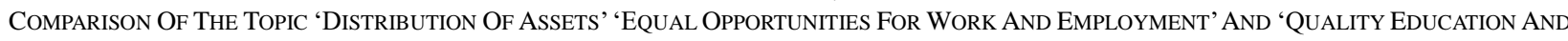
ACCESS TO KNOWLEDGE'

\begin{tabular}{|c|c|c|}
\hline Topics & \multicolumn{2}{c|}{ Occurs or Not (Y= Yes, N=No) } \\
\hline Distribution of Assets & Green Line New 6 (Germany) & Senior High English (China) \\
\hline $\begin{array}{c}\text { crowds } \\
\text { 1. Living, working and play together among races }\end{array}$ & $\mathrm{Y}$ & $\mathrm{N}$ \\
\hline $\begin{array}{c}\text { 2. Less access to meat and more about disappear into } \\
\text { 3. Economic stagnation of minority community }\end{array}$ & $\mathrm{Y}$ & $\mathrm{N}$ \\
\hline Equal Opportunities for Work and Employment & & $\mathrm{N}$ \\
\hline 1. A lack of working opportunities for UK immigrants & $\mathrm{Y}$ & $\mathrm{N}$ \\
\hline 2. Young Bangladeshi males with no employment & $\mathrm{Y}$ & $\mathrm{N}$ \\
\hline 3. Unemployment in South Africa & $\mathrm{Y}$ & $\mathrm{N}$ \\
\hline $\begin{array}{c}\text { 4. Business and the government are not doing enough } \\
\text { to hire young people and provide work experience }\end{array}$ & $\mathrm{Y}$ & \\
\hline Quality Education and Access to Knowledge & & $\mathrm{N}$ \\
\hline $\begin{array}{c}\text { 1.Bottom of rankings of educational achievement in } \\
\text { UK distribution }\end{array}$ & $\mathrm{Y}$ & $\mathrm{N}$ \\
\hline 2. Education has improved in South Africa & $\mathrm{Y}$ & \\
\hline Equal Rights between Women and Men & & \\
\hline 1. Unfair in career & $\mathrm{Y}$ & $\mathrm{N}$ \\
\hline 2. Domestic violence & $\mathrm{Y}$ & \\
\hline
\end{tabular}

The above repertoire of topics firstly articulates what is excluded from Senior High English series. These topics are associated with real-life society while they are not introduced to Chinese students in English texts. In the long run, Chinese students might face these social problems under despair, confusion and rebellion. Oppositely, students in Germany seem to be more genuinely exposed to social products because they explore different social aspects from what they read.

Health Services, Social Security and the Provision of a Safe Environment

Nevertheless, when selecting topics surrounding 'health services, social security and ensuring a safe environment', these textbooks are successful in introducing a range of topic categories. As Table 3 shows, both of Green Line New 6 and Senior High English series include topics about drug abuse, crime, violence, inadequate living conditions. What is notable is that Green Line New 6 provides English learners with literary passages about HIV/Aids and wildlife trade. Senior High English series employs texts to emphasise the topic of crime in cyberspace.

These texts aim to disseminate social problems around the world and to expose students in real social truths. Indeed, these topics are stimuli for class discussions, which can be justified from post-reading activities. For example, lesson 1, unit 4 in Senior High English 2 is 'tomorrow's world'. After reading the text, students need to voice their opinions about the question: "do you feel pessimistic or optimistic about the future of the Internet? Why"? Thus, the teacher can initiate class/group/pair discussions, and students have much freedom to express their ideas creatively.

TABLE 3

COMPARISON OF THE TOPIC 'HEALTH SERVICES, SOCIAL SECURITY AND THE PROVISION OF A SAFE ENVIRONMENT'

\begin{tabular}{|c|c|c|}
\hline Topics & \multicolumn{2}{|c|}{ Occurs or Not (Y= Yes, N=No) } \\
\hline $\begin{array}{c}\text { Health Services, Social Security and the Provision } \\
\text { of a Safe Environment }\end{array}$ & Green Line New 6 (Germany) & Senior High English (China) \\
\hline 1. Drug abuse & $\mathrm{Y}$ & $\mathrm{Y}$ \\
\hline 2. Crime & $\mathrm{Y}$ & $\mathrm{Y}$ \\
\hline 3. Violence & $\mathrm{Y}$ & $\mathrm{Y}$ \\
\hline 4. Bad living conditions & $\mathrm{Y}$ & $\mathrm{Y}$ \\
\hline 5. HIV/Aids & $\mathrm{Y}$ & $\mathrm{N}$ \\
\hline 6. Wildlife trade & $\mathrm{Y}$ & $\mathrm{N}$ \\
\hline
\end{tabular}

Opportunities for Civic and Political Participation

Table 4 presents topics surrounding 'civic and political participation' in Green Line New 6 and Senior High English series separately. Green Line New 6 covers most of the topic categories. What is standing out is that many topics involve students' political rights and voices. For instance, one excerpt titled How dare you describes how the character expresses anger about disrespect for the rights of young people: "Those days are over, mate. Look at America. Look at France, Australia, Germany. I mean, why does this stupid country always lag decades behind anywhere with any respect for the rights of young people? It's stupid, stupid, stupid!” (Green Line New 6, 2008, p. 46).

However, Senior High English series does not cover as many topics as Green Line New 6 does about political rights, but it includes the matter of 'protest against nuclear testing in the Asia Pacific'. Therefore, Senior High English Series put specific focuses on countries around the Pacific area. 
TABLE 4

COMPARISON OF THE TOPIC 'OPPORTUNITIES FOR CIVIC AND POLITICAL PARTICIPATION'

\begin{tabular}{|c|c|c|}
\hline Topics & \multicolumn{2}{|c|}{ Occurs or Not (Y= Yes, N=No) } \\
\hline Opportunities for Civic and Political Participation & Green Line New 6 (Germany) & Senior High English (China) \\
\hline 1. Student's opinion towards liberty & $\mathrm{Y}$ & $\mathrm{N}$ \\
\hline 2. Civil rights and democracy & $\mathrm{Y}$ & $\mathrm{N}$ \\
\hline 3. Freedom and equal rights movement & $\mathrm{Y}$ & $\mathrm{N}$ \\
\hline 4. Young people and students rights & $\mathrm{Y}$ & $\mathrm{N}$ \\
\hline 5. Respect each other & $\mathrm{Y}$ & $\mathrm{N}$ \\
\hline 6. Human rights abuse & $\mathrm{Y}$ & $\mathrm{N}$ \\
\hline 7. Political crimes & $\mathrm{Y}$ & $\mathrm{N}$ \\
\hline 8. Freedom of expression and assembly & $\mathrm{Y}$ & $\mathrm{N}$ \\
\hline 9. Protest against nuclear testing in Asia pacific & $\mathrm{N}$ & $\mathrm{Y}$ \\
\hline
\end{tabular}

\section{Ethnic and Other Minority Groups}

Table 5 shows that Green Line New 6 includes a variety of minority groups from different areas, such as Asia, Africa and Europe. Thus, Green Line New 6 achieves a balance among various minority groups. Therefore, students have opportunities to understand the diversity of the world. Nevertheless, Senior High English series only involve Maori, African slaves and Celt in texts. According to the analysis, the Senior High English series covers less diverse topics than Green Line New 6 regarding minority groups.

TABLE 5

COMPARISON OF THE TOPIC 'ETHNIC AND OTHER MINORITY GROUPS'

\begin{tabular}{|c|c|c|}
\hline Topics & \multicolumn{2}{|c|}{ Occurs or Not (Y= Yes, N=No) } \\
\hline & $\begin{array}{c}\text { Green Line New 6 } \\
\text { (Germany) }\end{array}$ & Senior High English (China) \\
\hline Ethnic and Other Minority Groups & Y & $\mathrm{N}$ \\
\hline 1. Muslims, Hindus and Sikhs from India & $\mathrm{Y}$ & $\mathrm{N}$ \\
\hline 2. Whites & $\mathrm{Y}$ & $\mathrm{N}$ \\
\hline 3. Asians & $\mathrm{Y}$ & $\mathrm{N}$ \\
\hline 4. British Pakistani & $\mathrm{Y}$ & $\mathrm{N}$ \\
\hline 5. Bangladeshis & $\mathrm{Y}$ & $\mathrm{N}$ \\
\hline 6. Hate groups & $\mathrm{Y}$ & $\mathrm{N}$ \\
\hline 7. Native Africans & $\mathrm{Y}$ & $\mathrm{N}$ \\
\hline 8. Racial segregation & $\mathrm{Y}$ & $\mathrm{Y}$ \\
\hline 9. Black power & $\mathrm{N}$ & $\mathrm{Y}$ \\
\hline 10. Maori & $\mathrm{N}$ & $\mathrm{Y}$ \\
\hline 11. African slaves & $\mathrm{N}$ & \\
\hline 12. Celt & & \\
\hline
\end{tabular}

Persons with Disabilities

Table 6 indicates that the diversity of topic 'persons with disabilities' is relegated and there are two topics identified across textbooks. In Green Line New 6, neither of them is involved in texts. However, Senior High English series incorporate disability-related issues. Therefore, Chinese students are offered opportunities to face challenges from life, respect disabled persons and fight against discrimination.

TABLE 6.

COMPARISON OF THE TOPIC 'PERSONS WITH DisABILITIES'

\begin{tabular}{|c|c|c|}
\hline Topics & \multicolumn{2}{|c|}{ Occurs or Not (Y= Yes, N=No) } \\
\hline & Green Line New 6 (Germany) & Senior High English (China) \\
\hline Persons with Disabilities & $\mathrm{N}$ & \\
\hline 1. Promoting medical research into back injuries & $\mathrm{N}$ & $\mathrm{Y}$ \\
\hline 2. Disabled people & $\mathrm{Y}$ \\
\hline
\end{tabular}

\section{EVALUATIONS AND CONSIDERATIONS}

Reading texts provide a framework for textbook constructions and an orientation for organising pre-reading and post-reading activities. Given analysis results, it seems that Green Line New 6 series is more inclusive with social justice topics than Senior High English series. German students are encouraged to take ownership to embrace social justice around the world. However, Senior High English series lacks stimulating social justice topics. That is, Chinese students get less opportunities than German students to get access to social justice issues presented in textbooks. Therefore, the contents of Chinese English textbooks should be refurbishing utilising integrating social topics.

A critical perspective on the representation of these topics infers that students may face choices between good and bad, positive and negative, moral and evil from what they read. If students read specific texts and choose the wrong way, 
such as using violence and taking drugs, then their identities are dramatically affected. High school students are in the fluctuating process of shaping their values, ideas and notions toward society, and they are affected by the external world This is called "impressionable years" which refer to a flexible and vulnerable time to change attitudes among adolescents and young adults (Gwon \& Jeong, 2018, p. 604). During adolescence and young adulthood, people tend to have potential attributes of impressionability, such as susceptibility, openness and malleability to attitude and behaviour change; susceptible to public concerns; being easily influenced and distracted by an external environment; sensitivity to stimuli and immaturity and being incapable of making a transparent and independent judgement (Gwon \& Jeong, 2018, p. 605). Young adult learners are sensitive to distractions, a part of which stems from descriptions in what they read. They tend to satisfy themselves and attain excitement by taking a try at new things which are presented in literary texts. Thus, integrating suitable social justice topics might increase the possibilities of young learners to choose the "wrong way of life". In the other way around, students who are ignorant of social truths tend to be confused about the unknown and are controlled by their curiosity toward evil things.

Therefore, this study calls for a thorough assessment by students, but this assessment cannot be complete without teachers' participation and positive guidance. It, therefore, requires teachers to offer students with the right volume information of social topics, to encourage them to reflect on such social issues and to ensure rational choices made by students.

\section{CONCLUSION}

This study investigated social justice topics of reading texts across three textbooks used in China and Germany. It bridges the gap between social justice education and textbooks and suggests a better understanding of what topics learners touch upon in China and Germany.

Despite its significance, it has limitations as well. For example, this study selects only three English textbooks and purely employs a qualitative research method. Thus, future research can recruit a larger number of samples and combine qualitative and quantitative approaches to provide a more comprehensive understanding of topics concerning social justice education.

\section{REFERENCES}

[1] Ashford. (2008). Learning English - Green Line New 6. Stuttgart: Ernst Klett Verlaf GmbH.

[2] Ahmad, H., \& Shah, S. R. (2014). EFL Textbooks: exploring the suitability of textbook contents from EFL teachers' perspective. VFAST Transactions on Education and Social Sciences, 5(1), 12-20.

[3] Alvaredo, F., Chancel, L., Piketty, T., Saez, E., \& Zucman, G. (2018). World Inequality Report 2018 Executive Summary. Wir2018.Wid.World, 20. <https://wir2018.wid.world/files/download/wir2018-summary-english.pdf> (accessed August 22, 2019).

[4] Cunningsworth, A. (1995). Choosing your coursebook. Oxford, England: Heinemann.

[5] Celce, M., \& Olshtain, E. (2000). Discourse and Context in Language Teaching. A guide for language teachers. New York: Cambridge University.

[6] Downey, L. (2005). Assessing environmental inequality: How the conclusions we draw vary according to the definitions we employ. Sociological Spectrum, 25(3), 349-369.

[7] Dover, A. G. (2013). Teaching for social justice: From conceptual frameworks to classroom practices. Multicultural perspectives, 15(1), 3-11.

[8] Gómez Rodríguez, L. F. (2015). The cultural content in EFL textbooks and what teachers need to do about it. Profile Issues in Teachers Professional Development, 17(2), 167-187.

[9] Gwon, S. H., \& Jeong, S. (2018). Concept analysis of impressionability among adolescents and young adults. Nursing Open, $5(4), 601-610$.

[10] Hsieh, H. F., \& Shannon, S. E. (2005). Three approaches to qualitative content analysis. Qualitative health research, 15(9), $1277-1288$.

[11] Hong Kong Education Bureau, the People's Republic of China. (2007). Learning and Teaching Resources for Learning English through Social Issues. <https://www.edb.gov.hk/attachment/en/curriculum-development/kla/eng-edu/social\%20issues_teaching \%20resources_071211.pdf> (accessed August 22, 2019).

[12] Letizia, A. J. (2016). Democracy and Social Justice Education in the Information Age. Cham: Springer International Publishing.

[13] McKay, S. (2003). Teaching English as an international language: The Chilean context. ELT Journal, 57(2), 139-148.

[14] Macgilchrist F. (2018) Materiality and Mediality of Textbooks. In: Fuchs E., Bock A. (eds) The Palgrave Handbook of Textbook Studies. Palgrave Macmillan, New York. https://doi.org/10.1057/978-1-137-53142-1_12.

[15] Neuendorf, K. A. (2002). The content analysis guidebook. Thousand Oaks, Calif: Sage Publications.

[16] Rumelhart, D. E. (1976). Toward an interactive model of reading. San Diego, California: Center for Human Information Processing, University of California.

[17] Stubbs, M. (1982). What is English? Modern English language in the curriculum. Linguistics and the Teachers. Ed. Ronald Carter. London: Routledge \& Kegan Paul. 137-156.

[18] United Nations. Division for Social Policy. (2006). Social justice in an open world: The role of the United Nations. United Nations Publications.

[19] Wang, Qiang. (2004). Senior High English 1 (Compulsory Module). Beijing: Beijing Normal University Group.

[20] Wang, Qiang. (2004). Senior High English 2 (Compulsory Module). Beijing: Beijing Normal University Group. 
Xiao Zhang is a doctoral student in the TESOL program of Ludwig-Maximilians-Universität München, Germany. Her research interests include teacher education, English as a lingua franca and intercultural communicative competence. She has published several articles in the field of English language teaching. She is also active in some TESOL international conferences. 